\title{
Use of Microspoilers for Control of Finned Projectiles
}

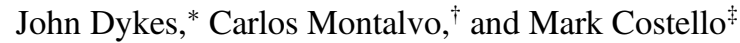 \\ Georgia Institute of Technology, Atlanta, Georgia 30332-0420 \\ and \\ Jubaraj Sahu $\underline{\S}$ \\ U.S. Army Research Laboratory, Aberdeen, Maryland 21005 \\ DOI: $10.2514 / 1 . A 32274$
}

\begin{abstract}
Due to space limitations, cost restrictions, and performance challenges, the physical control mechanism on a smart projectile plays a central role in the overall system design. Many different smart projectile control mechanisms have been created including aerodynamic-based mechanisms such as movable canards, propellant-based mechanisms such as squibs, and inertia-based mechanisms such as internal moving masses. The work reported here considers small microspoilers located between rear fins of a finned projectile to create aerodynamic load changes to enable projectile control. In particular, boundary-layer shock interaction between the projectile body, fins, and microspoilers provides a multiplicative effect on controllable forces and moments induced by microspoiler activation. A parametric study varying the microspoiler configuration is conducted to examine the level of control authority possible for this control mechanism concept. Results indicate that relatively small microspoilers located between fins generate substantial control authority that is capable of eliminating impact errors caused by muzzle jump, aerodynamic uncertainty, and atmospheric winds. These conclusions are based on computational fluid dynamic predictions of the effect of microspoilers on air loads coupled to a rigid six-degree-of-freedom projectile trajectory simulation.
\end{abstract}

\section{Nomenclature}

$a$

$C_{m}, C_{n 0}$

$C_{m q}$

$C_{\mathrm{NA}}$

$C_{X 0}$

$C_{X 2}$

$C_{Y 0}, C_{Z 0}$

$C_{l \delta} \delta$

$C_{l p}$

$D$

g

I

$K_{P}$

$K_{I}$

$K_{D}$

$L, M, N$ coefficient fin cant
$=$ speed of sound for air, $\mathrm{ft} / \mathrm{s}$

$=$ trim moment aerodynamic coefficients, perpendicular to projectile axis of symmetry

$=$ pitch damping moment aerodynamic

$=$ normal force aerodynamic coefficient

$=$ zero yaw axial force aerodynamic coefficient, parallel to projectile motion

$=$ yaw axial force aerodynamic coefficient, parallel to projectile motion

$=$ trim force aerodynamic coefficients, perpendicular to projectile axis of symmetry

$=$ roll moment aerodynamic coefficient from

$=$ roll damping aerodynamic coefficient

$=$ projectile reference diameter, $\mathrm{ft}$

$=$ acceleration due to gravity, $9.81 \mathrm{~m} / \mathrm{s}^{2}$

$=$ projectile inertia tensor matrix, slug- $\mathrm{ft}^{2}$

$=$ controller proportional gain

$=$ controller integral gain

$=$ controller derivative gain

$=$ external moment components on the projectile body expressed in the projectile reference frame, ft-lbf

Presented as Paper 2010-8246 at the 2010 AIAA Atmospheric Flight Mechanics Conference, Toronto, ON, 17-19 August 2010; received 4 November 2011; revision received 15 March 2012; accepted for publication 2 April 2012. Copyright $\odot 2012$ by the American Institute of Aeronautics and Astronautics, Inc. All rights reserved. Copies of this paper may be made for personal or internal use, on condition that the copier pay the $\$ 10.00$ per-copy fee to the Copyright Clearance Center, Inc., 222 Rosewood Drive, Danvers, MA 01923; include the code 0022-4650/12 and \$10.00 in correspondence with the CCC.

${ }^{*}$ Research Assistant, School of Mechanical Engineering. Student Member AIAA.

${ }^{\dagger}$ Research Assistant, School of Aerospace Engineering. Student Member AIAA.

Sikorsky Associate Professor, School of Aerospace Engineering. Associate Fellow AIAA.

${ }^{\S}$ Research Scientist, Weapons and Materials Research Directorate. Fellow AIAA.

$$
\begin{aligned}
& L_{\mathrm{SA}}, M_{\mathrm{SA}}, N_{\mathrm{SA}}=\text { steady aerodynamic moment components on } \\
& L_{\mathrm{UA}}, M_{\mathrm{UA}}, N_{\mathrm{UA}}=\text { unsteady aerodynamic moment components } \\
& \text { on the projectile body expressed in the } \\
& \text { projectile reference frame, } \mathrm{ft}-\mathrm{lbf} \\
& L_{C}, M_{C}, N_{C} \quad=\text { microspoiler moment components on the } \\
& \text { projectile body expressed in the projectile } \\
& \text { reference frame, ft-lbf } \\
& \mathrm{Ma} \quad=\text { Mach number, nd } \\
& m \quad=\text { projectile mass, slugs } \\
& p, q, r \quad=\text { components of the angular velocity vector of } \\
& \text { the projectile body expressed in the } \\
& \text { projectile reference frame, } \mathrm{rad} / \mathrm{s} \\
& t \quad=\text { time, } \mathrm{s} \\
& t_{a} \quad=\text { control system maneuver activation time, } \mathrm{s} \\
& u, v, w \quad=\text { translation velocity components of the } \\
& \text { projectile center of mass expressed in the } \\
& \text { projectile reference frame, } \mathrm{ft} / \mathrm{s} \\
& V \quad=\text { velocity magnitude of projectile center of } \\
& \text { mass, } \mathrm{ft} / \mathrm{s} \\
& X, Y, Z=\text { total external force components on the } \\
& \text { projectile body expressed in the projectile } \\
& \text { reference frame, } l b f \\
& X_{A}, Y_{A}, Z_{A} \quad=\text { aerodynamic force components on the } \\
& \text { projectile body expressed in the projectile } \\
& \text { reference frame, lbf } \\
& X_{C}, Y_{C}, Z_{C} \quad=\text { microspoiler force components on the } \\
& \text { projectile body expressed in the projectile } \\
& \text { reference frame, lbf } \\
& X_{G}, Y_{G}, Z_{G}=\text { gravitational force components on the }
\end{aligned}
$$




$\begin{array}{ll}\rho & =\text { density of air, slugs } / \mathrm{ft}^{3} \\ \sigma_{\mathrm{MW}} & =\text { atmospheric mean wind intensity, } \mathrm{ft} / \mathrm{s} \\ \psi_{\mathrm{MW}} & =\text { atmospheric wind azimuth angle, } \mathrm{deg} \\ \varphi, \theta, \psi & =\text { Euler roll, pitch, and yaw angles, deg }\end{array}$

\section{Introduction}

D IRECT-FIRE projectiles are fired by line-of-sight aiming from ground-based platforms, helicopters, and fixed-wing aircraft. A number of conditions can cause projectiles to miss an intended target. These conditions include manufacturing inaccuracies of the gun tube, propellant, and projectile, along with variable atmospheric conditions, firing platform motion, and aiming errors. With the advent of low-cost, small, rugged microelectro-mechanical systems, dramatic reduction in dispersion for direct-fire projectiles equipped with a flight control system is possible. The control mechanisms must be capable of altering the trajectory of the projectile in such a way that impact point errors induced at launch and in-flight can be corrected. At the same time, the control mechanism must be rugged to withstand high-acceleration loads at launch, small so that payload space is not compromised, and inexpensive for cost considerations [1]. Many different control mechanisms are being developed with these requirements in mind with three main categories of concepts: aerodynamic load mechanisms, jet thrust mechanisms, and inertial load mechanisms [2,3]. Examples of aerodynamic control mechanisms include rotation of aerodynamic lifting surface appendages, deflection of the nose, and deflection of ram air-to-side ports. Examples of jet thrust control mechanisms include gas jet thrusters and explosive thrusters, while examples of inertial control mechanisms include internal translation of a control mass and internal rotation of an unbalanced part.

The control mechanism investigated in this paper falls into the category of an aerodynamic mechanism, where small microspoilers are used to induce an aerodynamic force and moment perturbation on high-speed projectiles due to shock wave interaction between the fins, body, and microspoilers. Massey et al. [4], Massey and Guthrie []], Massey and Silton [] ], and Bell et al. [7] considered protuberance effects on fin-body interactions of high-speed projectiles. Both computational and experimental analysis showed that significant force multiplication can exist by modifying the boundary-layer shock interaction of the projectile fin and body. The devices used in these previous studies were relatively large (on the order of one third the fin height) and protruded beyond the boundary layer. Large and

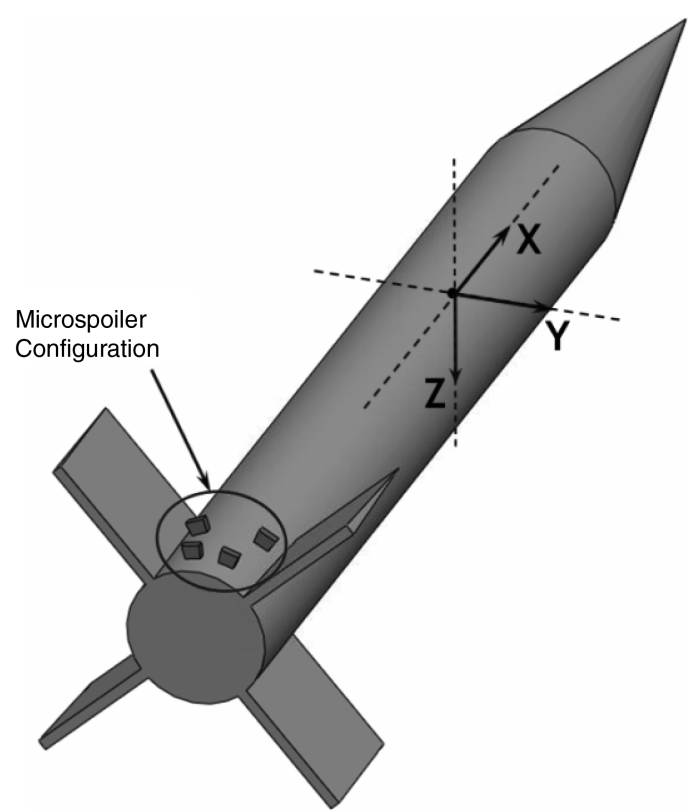

Fig. 1 Schematic of an Army-Navy finned projectile possessing a onequadrant microspoiler control mechanism configuration. controllable aerodynamic load perturbations were noted. A similar physical control mechanism is considered here. A number of small microspoilers are inserted between the rear fins of the projectile. Figure 1 provides a schematic of a finned projectile equipped with microspoilers. The microspoilers are activated in a coordinated fashion to generate maximal control authority. A set of parametric trade studies are conducted on microspoiler configurations, and its effects on control authority are reported. Furthermore, active control performance of a nominal microspoiler configuration is presented to establish the promise of this projectile control mechanism. Results presented in this article are based on flight dynamic simulation using a rigid body representation. Prediction of the effects of microspoiler deflection on aerodynamic loads is produced using computational fluid dynamics (CFD) analysis. Details on these models are given below, followed by presentation of microspoiler performance predictions.

\section{Projectile Dynamic Model}

The nonlinear trajectory simulation used in this study is a standard six-degree-of-freedom model typically used in flight dynamic modeling of projectiles. These six degrees of freedom include three inertial components of the position vector and three standard Euler projectile orientation angles, referenced to an "Earth-fixed" inertial frame. The equations of motion are provided in Eqs. (1-4), as derived by McCoy [ㅁ] and Murphy [ㅁ]

$$
\begin{aligned}
& \left\{\begin{array}{c}
\dot{x} \\
\dot{y} \\
\dot{z}
\end{array}\right\}=\left[\begin{array}{ccc}
c_{\theta} c_{\psi} & s_{\phi} s_{\theta} c_{\psi}-c_{\phi} s_{\psi} & c_{\phi} s_{\theta} c_{\psi}+s_{\phi} s_{\psi} \\
c_{\theta} s_{\psi} & s_{\phi} s_{\theta} s_{\psi}+c_{\phi} c_{\psi} & c_{\phi} s_{\theta} s_{\psi}-s_{\phi} c_{\psi} \\
-s_{\theta} & s_{\phi} c_{\theta} & c_{\phi} c_{\theta}
\end{array}\right]\left\{\begin{array}{c}
u \\
v \\
w
\end{array}\right\} \\
& \left\{\begin{array}{c}
\dot{\phi} \\
\dot{\theta} \\
\dot{\psi}
\end{array}\right\}=\left[\begin{array}{ccc}
1 & s_{\phi} t_{\theta} & c_{\phi} t_{\theta} \\
0 & c_{\phi} & -s_{\phi} \\
0 & s_{\phi} / c_{\theta} & c_{\phi} / c_{\theta}
\end{array}\right]\left\{\begin{array}{l}
p \\
q \\
r
\end{array}\right\} \\
& \left\{\begin{array}{c}
\dot{u} \\
\dot{v} \\
\dot{w}
\end{array}\right\}=\left\{\begin{array}{c}
X / m \\
Y / m \\
Z / m
\end{array}\right\}-\left[\begin{array}{ccc}
0 & -r & q \\
r & 0 & -p \\
-q & p & 0
\end{array}\right]\left\{\begin{array}{c}
u \\
v \\
w
\end{array}\right\} \\
& \left\{\begin{array}{c}
\dot{p} \\
\dot{q} \\
\dot{r}
\end{array}\right\}=[I]^{-1}\left[\left\{\begin{array}{c}
L \\
M \\
N
\end{array}\right\}-\left[\begin{array}{ccc}
0 & -r & q \\
r & 0 & -p \\
-q & p & 0
\end{array}\right][I]\left\{\begin{array}{c}
p \\
q \\
r
\end{array}\right\}\right]
\end{aligned}
$$

In Eqs. (1) and (2), the standard shorthand notation for trigonometric functions is used: $s_{\alpha}=\sin (\alpha), c_{\alpha}=\cos (\alpha)$, and $t_{\alpha}=\tan (\alpha)$. The forces $(X, Y, Z)$ appearing in Eq. (3) contain contributions from gravity $G$, body aerodynamics $A$, and microspoiler control $C$ and are shown in Eq. (5):

$$
\left\{\begin{array}{c}
X \\
Y \\
Z
\end{array}\right\}=\left\{\begin{array}{c}
X_{G} \\
Y_{G} \\
Z_{G}
\end{array}\right\}+\left\{\begin{array}{c}
X_{A} \\
Y_{A} \\
Z_{A}
\end{array}\right\}+\left\{\begin{array}{c}
X_{C} \\
Y_{C} \\
Z_{C}
\end{array}\right\}
$$

The dynamic equations are expressed in a body fixed reference frame, thus all forces acting on the body are expressed in the projectile reference frame. The force acting due to gravity is shown in Eq. (6):

$$
\left\{\begin{array}{l}
X_{G} \\
Y_{G} \\
Z_{G}
\end{array}\right\}=m g\left\{\begin{array}{c}
-s_{\theta} \\
s_{\phi} c_{\theta} \\
c_{\phi} c_{\theta}
\end{array}\right\}
$$

The body aerodynamic force acting at the center of pressure of the projectile is given by Eq. (7): 


$$
\left\{\begin{array}{c}
X_{A} \\
Y_{A} \\
Z_{A}
\end{array}\right\}=\frac{\pi}{8} \rho V^{2} D^{2}\left\{\begin{array}{c}
C_{X 0}+C_{X 2}\left(v^{2}+w^{2}\right) / V^{2} \\
C_{Y 0}+C_{\mathrm{NA}} v / V \\
C_{Z 0}+C_{\mathrm{NA}} w / V
\end{array}\right\}
$$

The applied moments about the projectile mass center contains contributions from steady aerodynamics $\mathrm{SA}$, unsteady aerodynamics $\mathrm{UA}$, and the microspoiler control $C$.

$$
\left\{\begin{array}{c}
L \\
M \\
N
\end{array}\right\}=\left\{\begin{array}{c}
L_{\mathrm{SA}} \\
M_{\mathrm{SA}} \\
N_{\mathrm{SA}}
\end{array}\right\}+\left\{\begin{array}{c}
L_{\mathrm{UA}} \\
M_{\mathrm{UA}} \\
N_{\mathrm{UA}}
\end{array}\right\}+\left\{\begin{array}{c}
L_{C} \\
M_{C} \\
N_{C}
\end{array}\right\}
$$

The moment components due to steady aerodynamic forces and control forces are computed with a cross product between the distance vector from the mass center to the location of the specific force and the force itself. The unsteady body aerodynamic moment provides a damping source for projectile angular motion, as given by Eq. (9):

$$
\left\{\begin{array}{c}
L_{\mathrm{SA}} \\
M_{\mathrm{SA}} \\
N_{\mathrm{SA}}
\end{array}\right\}=\frac{\pi}{8} \rho V^{2} D^{3}\left\{\begin{array}{c}
C_{l \delta} \delta+\frac{D C_{l p}}{2 V} p \\
c_{m 0}+\frac{D C_{m q}}{D V} q \\
c_{n 0}+\frac{D C_{m q}}{2 V} r
\end{array}\right\}
$$

The projectile mass, center of gravity, and inertial properties are all assumed to be constant throughout the duration of the flight. The center of pressure location and all aerodynamic coefficients depend on local Mach number and are computed during simulation using linear interpolation. The dynamic equations given by Eqs. (1- $\underline{4})$ are numerically integrated forward in time using a fourth-order, fixed-step Runge-Kutta algorithm. Costello and Anderson [10] present correlation of this dynamic model against range data for a finstabilized projectile.

\section{Determination of Microspoiler Aerodynamic Perturbations}

Note that the forces and moments depicted in Eqs. (7) and (9) include aerodynamic forces and moments created by the projectile without microspoilers activated. To obtain the total aerodynamic effects of the microspoilers, a two-part estimation technique is used. First, a projectile is simulated using a combined CFD and rigid body dynamic simulation (CFD/RBD) algorithm. The CFD/RBD simulation combines the rigid six degree-of-freedom flight dynamic model explained previously with a three-dimensional, time-accurate CFD simulation. This combination is achieved by simultaneously integrating the fluid and rigid body dynamic equations of motion. This method is referred to as the virtual flyout method as it simulates a projectile trajectory virtually from first principles. Details are given in $[11,12]$. The virtual flyout method predicts the position, orientation, translational velocity, angular velocity, and total aerodynamic loads at discrete points along the trajectory. Projectile state information (position, orientation, translational velocity, angular velocity) and aerodynamic loads (forces and moments) form a basic data set that is used to estimate a flight dynamic aerodynamic model for the projectile with and without the microspoilers activated. All aerodynamic coefficients in Eqs. (7) and (8) are estimated with a specialized output error parameter estimation algorithm that is detailed in [13].

Virtual flyout simulations were generated at Mach 2.0, 2.5, and 3.0 launch conditions to obtain the aerodynamic effects of the microspoilers over a range of speeds. The initial conditions of the two flyouts are shown in the Table $\underline{1}$ and the resulting changes in aerodynamic coefficients are shown in Table 2. As seen from these tables the primary effect of the microspoiler is creating an aerodynamic asymmetry, which can be seen in the increase of $C_{Z 0}$ and $C_{m 0}$. There is also indication of a drastic change in the aerodynamic roll and pitch damping. This is clearly due to the disruption of the flow around the fins, which has the most aerodynamic influence on the projectile.
Table 1 Initial conditions of virtual flyouts

\begin{tabular}{lccc}
\hline \hline Position, ft & Attitude, rad & Velocity, Mach number & Attitude rates, rad $/ \mathrm{s}$ \\
\hline$x=0$ & $\varphi=0$ & $u=2,2.5$, and 3 & $p=50$ \\
$y=0$ & $\theta=0$ & $v=0$ & $q=10$ \\
$z=0$ & $\psi=0$ & $w=0$ & $r=0$ \\
\hline \hline
\end{tabular}

Table 2 Delta coefficients for microspoilers

\begin{tabular}{lrrr}
\hline & Mach 2 & Mach 2.5 & \multicolumn{1}{c}{ Mach 3 } \\
\hline$C_{X 0}$ & 0.069 & 0.055 & 0.056 \\
$C_{Z 0}$ & -0.198 & -0.154 & -0.106 \\
$C_{l p}$ & -0.915 & -0.953 & -1.963 \\
$C_{\mathrm{NA}}$ & 0.061 & 0.122 & 0.136 \\
$C_{m 0}$ & 0.192 & 0.244 & 0.260 \\
SLCOP, ft & -0.006 & -0.007 & -0.002 \\
$C_{m q}$ & & -149.047 & -136.327 \\
\hline \hline
\end{tabular}

\section{Flight Dynamic Analysis}

\section{A. Description of Projectile and Microspoiler Configuration}

To examine the effectiveness of the microspoiler control mechanism, trajectory results were generated for an example testbed projectile. The U.S. Army-Navy finned projectile was selected for this study as an example of a direct fire fin-stabilized projectile [13]. Figure 1 presents a schematic of this projectile. From Dupuis [ $[\overline{12}]$, the projectile mass, diameter, mass center measured along the station line, roll inertia, and pitch inertia are 0.108851 slugs, $0.098425 \mathrm{ft}$, $0.4429 \mathrm{ft}, 0.000142$ slugs- $\mathrm{ft}^{2}$, and 0.00728 slugs- $\mathrm{ft}^{2}$, respectively. The fins are canted to an angle of $0.25 \mathrm{deg}$ to induce a moderate roll rate. The geometry of the projectile is shown in Fig. $\underline{2}$, where each fin on the projectile is 30.0 by $30.0 \mathrm{~mm}$.

Each of the four microspoilers in a given configuration is $3.0 \mathrm{~mm}$ wide and approximately $4.5 \mathrm{~mm}$ tall. The deflection angle between the microspoiler and the projectile body is $90.0 \mathrm{deg}$. The two forward microspoilers are oriented $20.0 \mathrm{deg}$ from the nearest fin, while the two rearward microspoilers are oriented at a $40.0 \mathrm{deg}$ roll from the near fin. The forward and rearward microspoilers are 25.0 and $13.0 \mathrm{~mm}$ from the rear of the projectile, respectively.

\section{B. Single Trajectory Results}

Using the flight dynamics model previously discussed, a set of typical trajectory results were generated to demonstrate the basic effect of the microspoiler aerodynamic perturbations on projectile motion. The projectile initial conditions are $x=0.0 \mathrm{ft}, y=0.0 \mathrm{ft}$, $z=-10.0 \mathrm{ft}, \phi=0.0 \mathrm{deg}, \quad \theta=1.02863 \mathrm{deg}, \quad \psi=0.0 \mathrm{deg}$, $u=3357.0 \mathrm{ft} / \mathrm{s}, v=0.0 \mathrm{ft} / \mathrm{s}, w=0.0 \mathrm{ft} / \mathrm{s}, q=0.0 \mathrm{rad} / \mathrm{s}$, and $r=0.0 \mathrm{rad} / \mathrm{s}$. Microspoiler sets are located between all fins. As the projectile rolls in-flight, spoilers are sequentially activated and deactivated, causing the projectile to deflect from its natural trajectory.

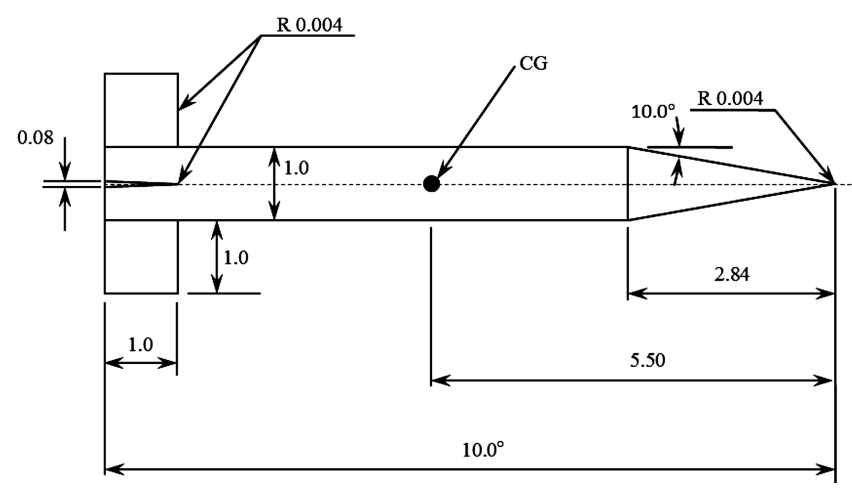

Fig. 2 U.S. Army-Navy finner geometry (all dimensions in calibers, 1 caliber $=30 \mathrm{~mm}$ ). 


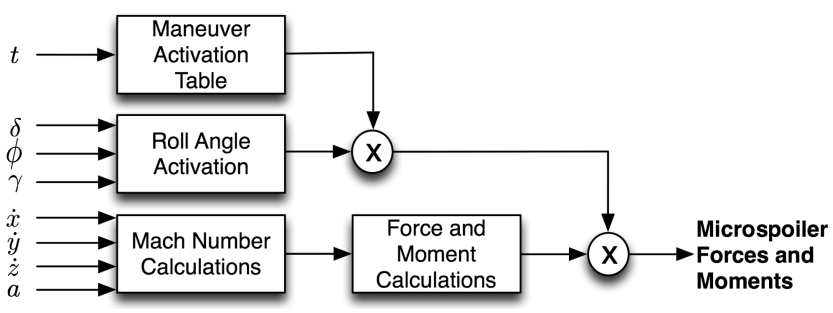

Fig. 3 Block diagram modeling of microspoiler perturbation forces and moments.

Shown in Fig. 3 , a simple flight control system is used to compute microspoiler activation to execute an inertial frame turn maneuver, given flight time and roll angle activation switches. Control authority of the system is significantly affected by maneuver activation time after launch $t_{a}$, command turn angle $\gamma$, and roll angle activation window $\delta$. The command turn angle represents the roll angle where the maximal outward lateral force is generated. The roll angle activation window is a roll angle band, centered on the command turn angle where the microspoilers are activated. Outside of this roll angle band, the microspoilers are not activated. A small activation window indicates microspoilers between two fins are activated over a small portion of the roll cycle. For a nominal case, $t_{a}=1.0 \mathrm{~s}$, $\gamma=180 \mathrm{deg}$, and $\delta=60.0 \mathrm{deg}$.

Figures 4-12 compare single trajectory results for an uncontrolled projectile and a full-left-turn controlled projectile. Figure 4 presents cross range out to a range of $3.0 \mathrm{~km}$. Because the $y$ axis is oriented to the right, a negative value of the $y$ coordinate refers to a left turn. The controlled projectile trajectory deflects $193.9 \mathrm{~m}$. Figure 5 shows minor differences in altitude between controlled and uncontrolled projectiles. Time histories of the Euler pitch and roll angles are given in Figs. 6 and 7, where it is shown that activating the control mechanism introduces oscillatory orientation perturbations. Note that while the maneuver-controlled pitch angle does follow the uncontrolled pitch angle, the maneuver-controlled yaw angle diverges from the uncontrolled case from 0.0 to nearly $-11.01 \mathrm{deg}$. Table 2 shows that the activation of the microspoilers creates an aerodynamic asymmetry at the rear of the projectile, thus creating a side force and a moment. Because the microspoilers are activated to induce a left turn, the moment created is a negative yaw rate, thus producing a large change in the projectile yaw angle. The small perturbation in the pitch angle can be attributed to gyroscopic moments from the slowly spinning projectile. Figure 8 shows that the roll rate is also reduced by over $10.0 \mathrm{rad} / \mathrm{s}$ after activation. Again from Table 2 the roll damping of the projectile is increased. This is due to the disruption of flow

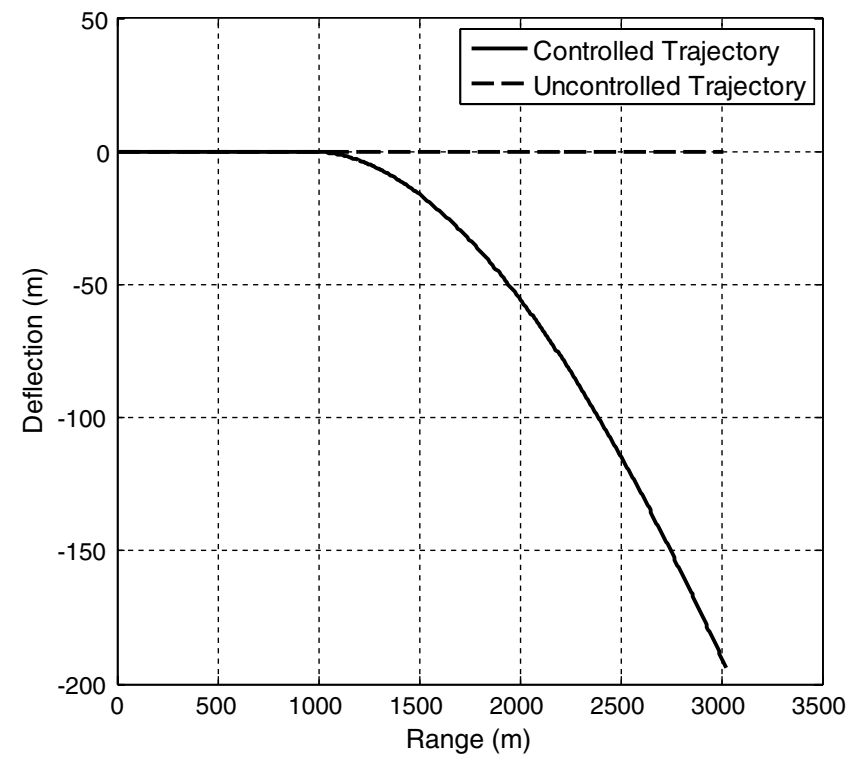

Fig. 4 Deflection vs range.

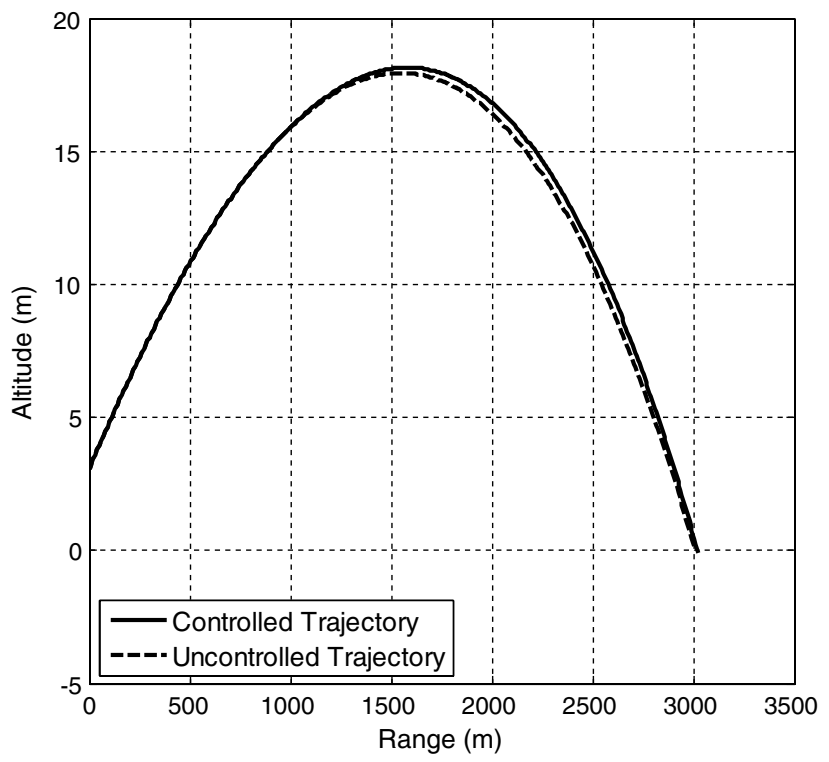

Fig. 5 Altitude vs range.

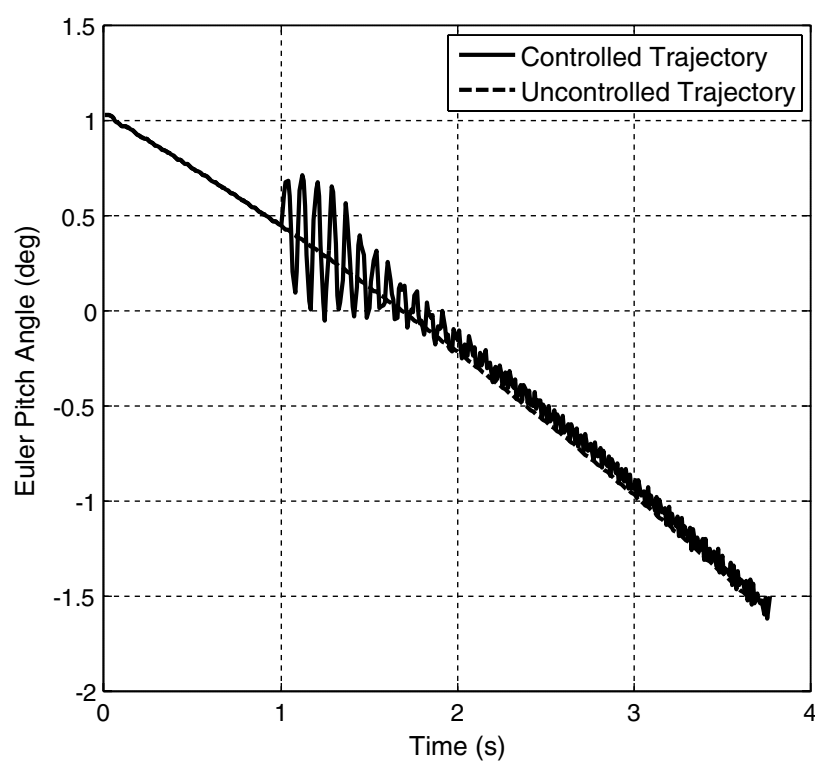

Fig. 6 Pitch angle vs time.

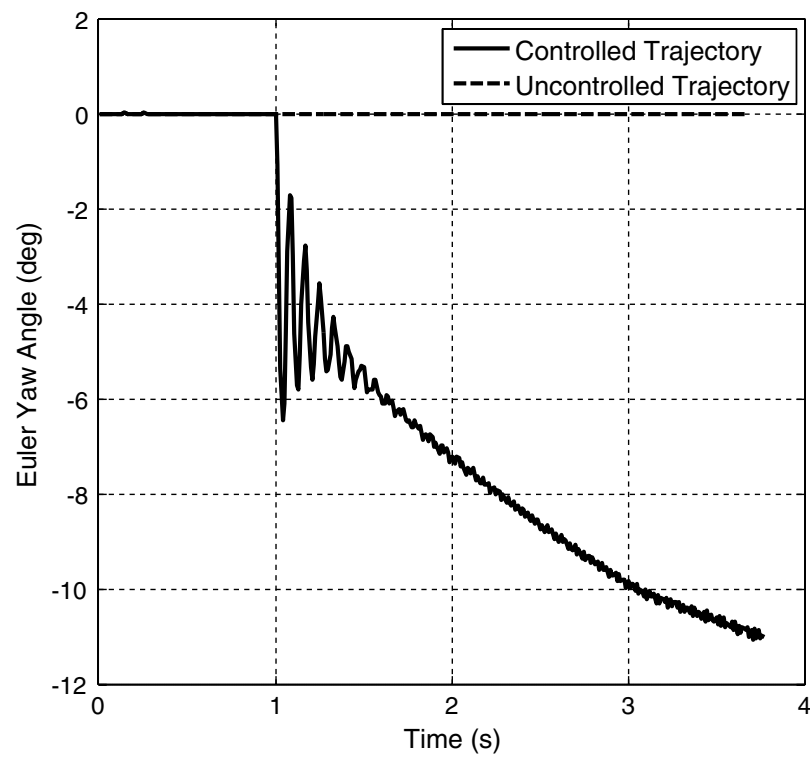

Fig. 7 Yaw angle vs time. 


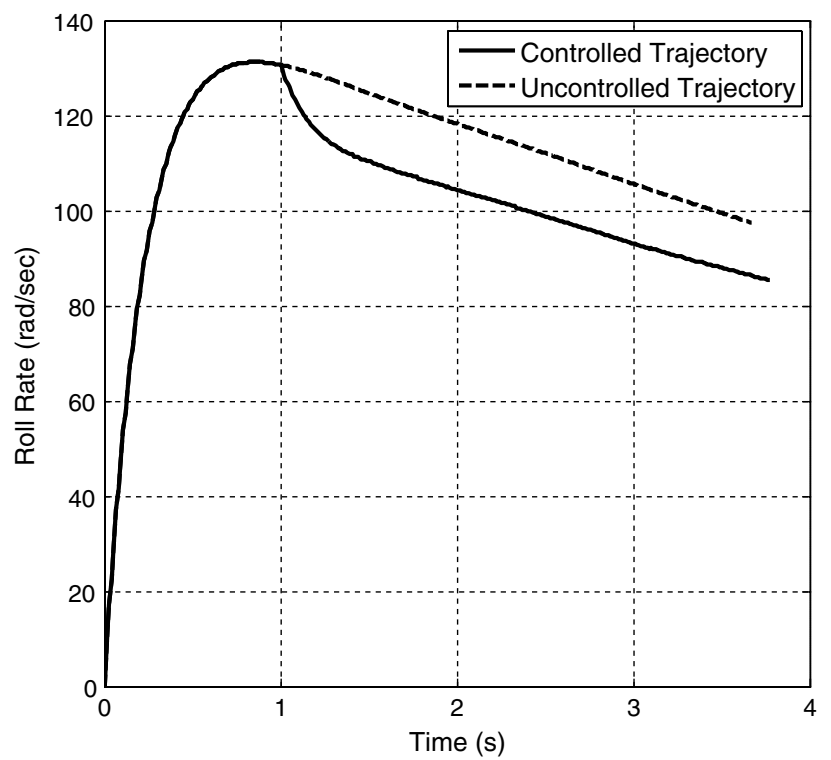

Fig. 8 Roll rate vs time.

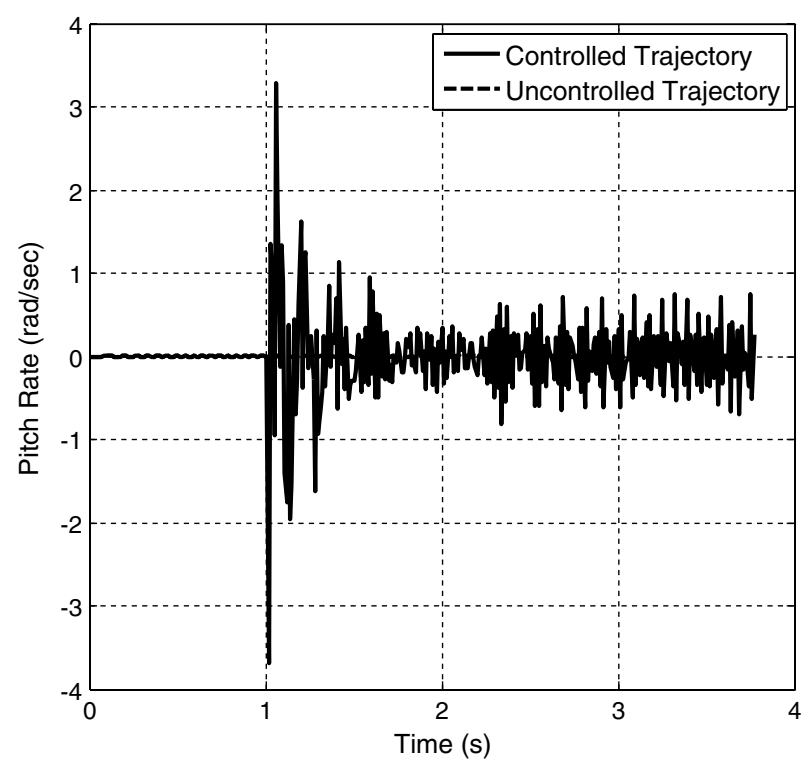

Fig. 9 Pitch rate vs time.

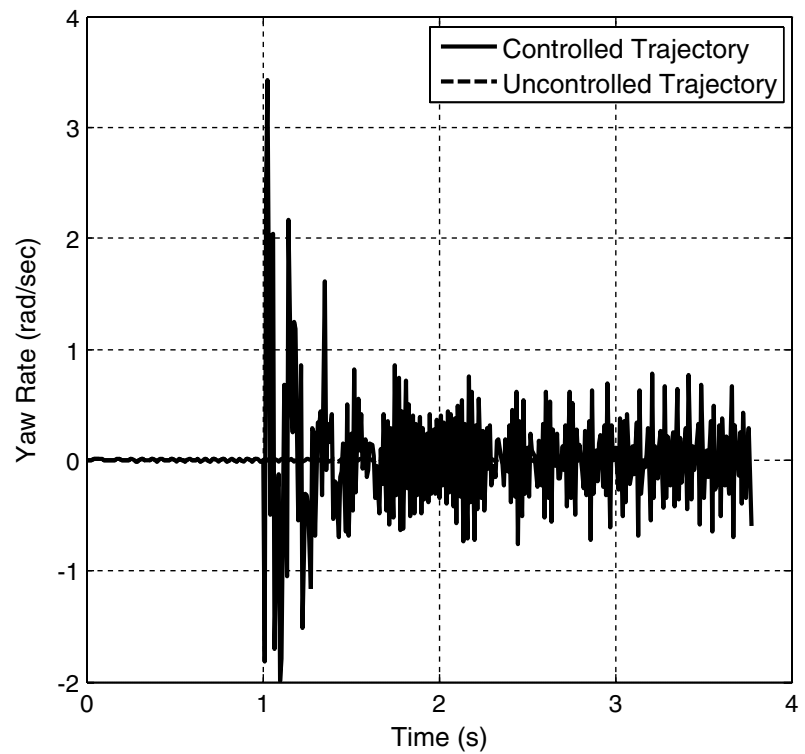

Fig. 10 Yaw rate vs time.

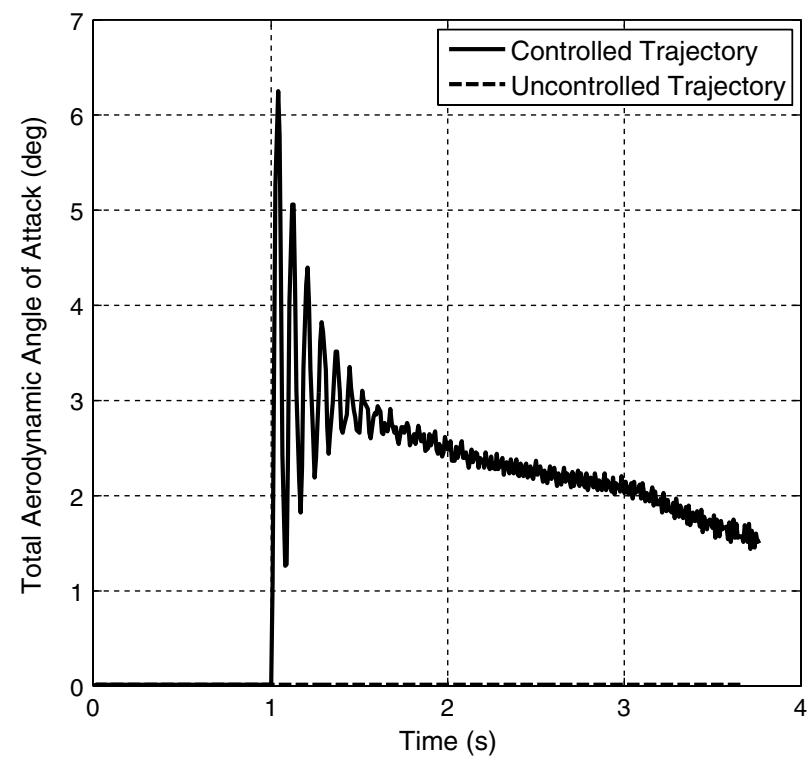

Fig. 11 Angle of attack vs time.

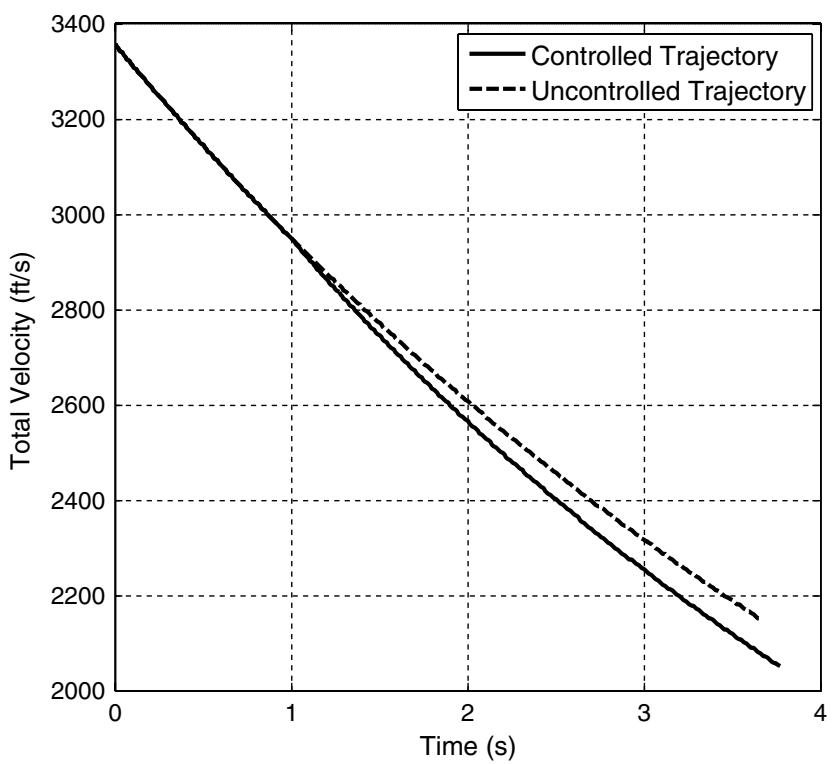

Fig. 12 Total velocity vs time.

between the fins causing more drag on the fins, creating more roll damping. Maximal pitch and yaw rates never exceed $4.0 \mathrm{rad} / \mathrm{s}$ in amplitude (Figs. 9 and 10). In Fig. 11 the projectile total aerodynamic angle of attack experiences oscillations immediately after control activation to a maximum angle of $6.2 \mathrm{deg}$ but dampens down to below $2.6 \mathrm{deg}$ in just over $1.0 \mathrm{~s}$ of activation. Total velocity for the controlled projectile is slightly reduced from the uncontrolled case (Fig. 12). Figure 13 shows microspoiler total force and moment perturbations in a body-fixed frame, which are successively roll activated with decreasing magnitude from approximate maximums of $11.46 \mathrm{lbf}$ and $3.78 \mathrm{ft}-\mathrm{lbf}$ as the projectile decelerates.

\section{Control Authority Parametric Trade Study}

Several parametric trade studies were computed to examine the control authority of the microspoiler mechanism on the basic finned projectile recently described to a range of $3.0 \mathrm{~km}$. In all of the following results the nominal projectile initial conditions are $x=$ $0.0 \mathrm{ft}, y=0.0 \mathrm{ft}, z=-10.0 \mathrm{ft}, \phi=0.0 \mathrm{deg}, \theta=1.02863 \mathrm{deg}$, $\psi=0.0 \mathrm{deg}, u=3357.0 \mathrm{ft} / \mathrm{s}, \quad v=0.0 \mathrm{ft} / \mathrm{s}, \quad w=0.0 \mathrm{ft} / \mathrm{s}, q=$ $0.0 \mathrm{rad} / \mathrm{s}$, and $r=0.0 \mathrm{rad} / \mathrm{s}$. Also, nominal conditions for the control system parameters are set to $t_{a}=1.0 \mathrm{~s}$ and $\delta=60.0 \mathrm{deg}$, where $\gamma$ is spanned from 0.0 to $360.0 \mathrm{deg}$ in increments of $5.0 \mathrm{deg}$ to 


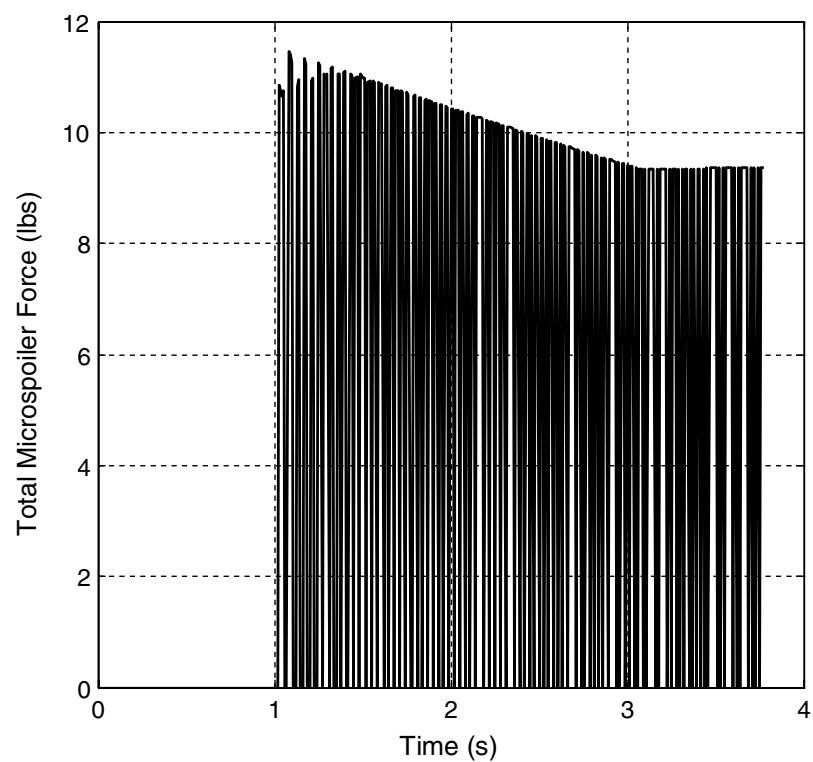

a)

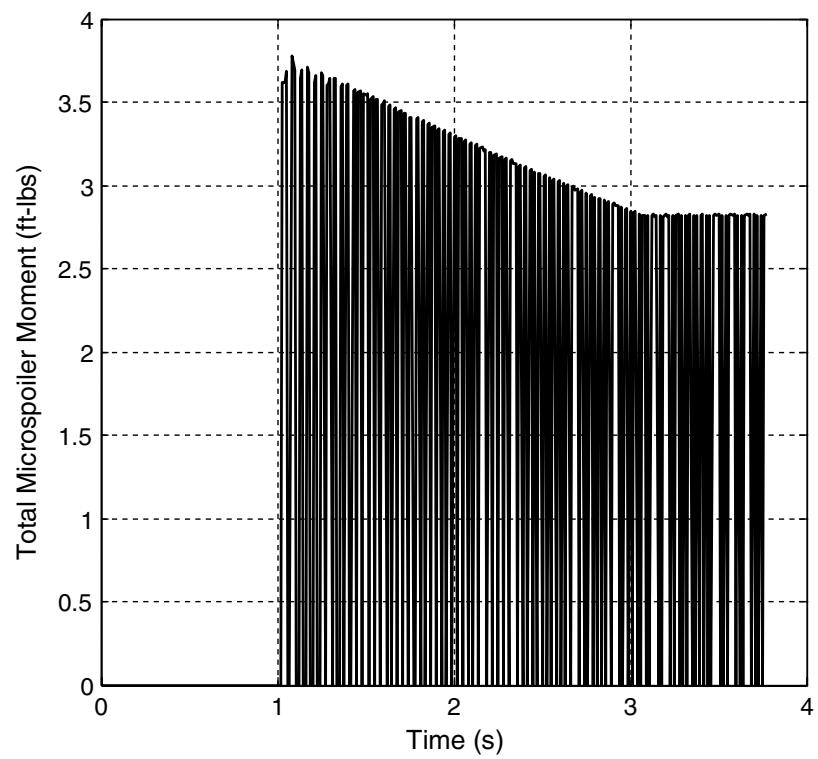

b)

Fig. 13 Graphs of a) total microspoiler perturbation force vs time, and b) total microspoiler perturbation moment vs time.

produce a complete control authority footprint, as shown in Fig. 14. Trade studies include variation of control mechanism configuration, activation time, launch velocity, and roll angle activation window and are summarized in Figs. 15-18.

Control authority linearly increases with increasing number of mechanisms (Fig. 15). MSC1, MSC2, MSC3, and MSC4 represent the number of microspoiler control mechanisms implemented between the projectile fins (from one up to four fin quadrants). Figure 16 shows that increasing the roll angle activation window has a positive effect on control authority, but the effect of the effect decreases slightly after about $90.0 \mathrm{deg}$. Increasing muzzle velocity has a positive effect on control authority (Fig. 17) while delaying controller activation time has a negative effect on control authority (Fig. 18).

\section{Active Control Analysi}

An active control system is simulated to demonstrate the capabilities of the microspoiler control mechanism to overcome typical launch and in-flight errors. This controller was designed to

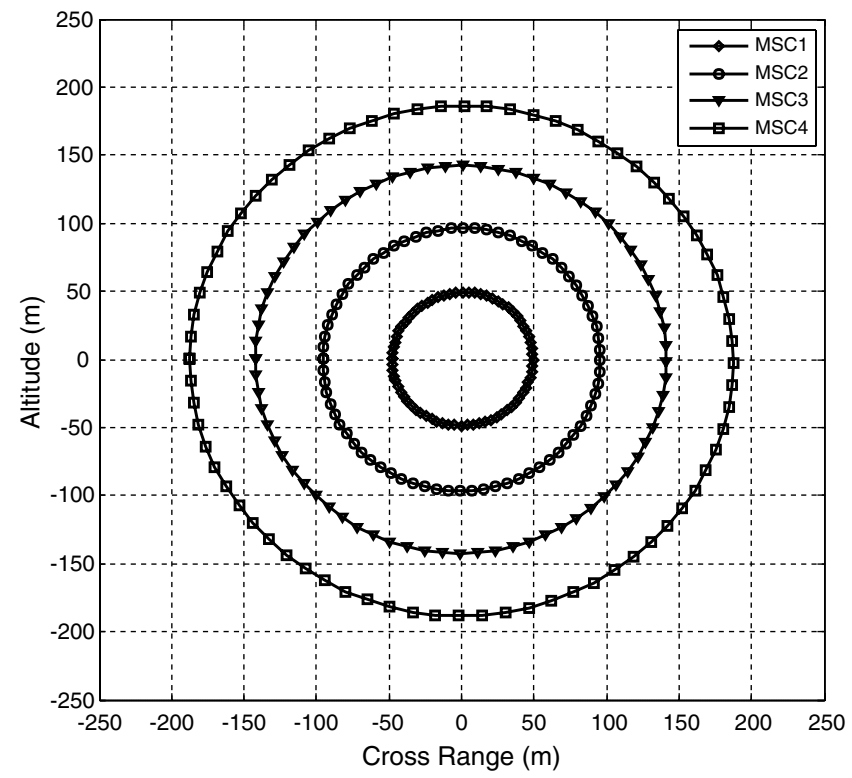

Fig. 14 Full control authority dispersion map for variation in microspoiler configuration (MSC) at an impact range of $3.0 \mathrm{~km}$ with nominal conditions: $t_{a}=1.0 \mathrm{~s}, \delta=60 \mathrm{deg}$, and $M a_{i}=3.0$.

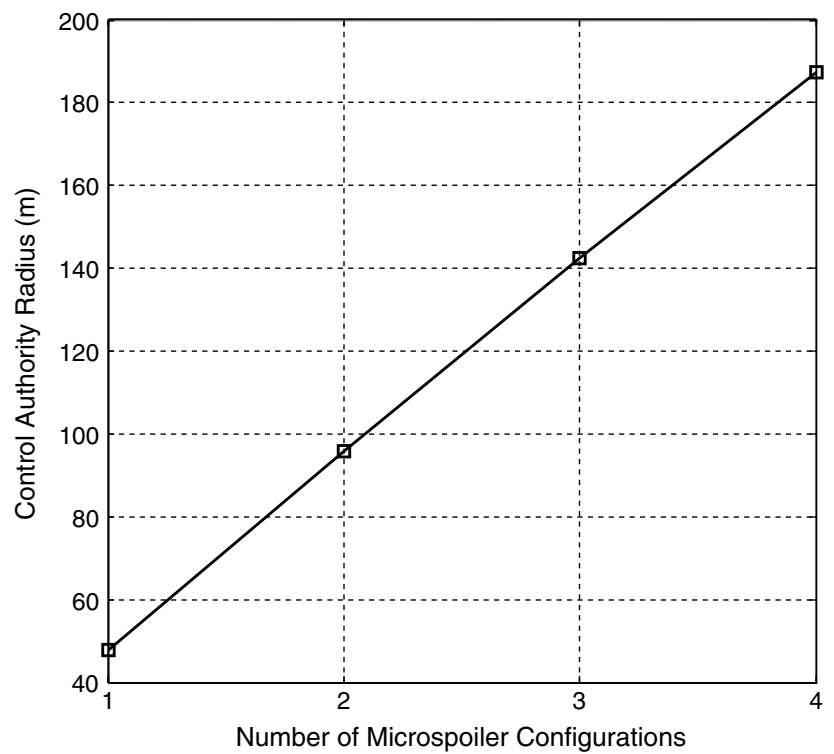

Fig. 15 Trade study: effect of varied MSCs on full control authority with nominal conditions: $t_{a}=1.0 \mathrm{~s}, \delta=60 \mathrm{deg}$, and $M a_{i}=3.0$.

track a user-specified commanded ballistic trajectory through use of Global Positioning System and other onboard sensors to provide feedback of $x, y, z$, and $\varphi$ for the entire flight. The algorithm illustrated in Fig. 19 uses the command trajectory to develop an inertial projectile error vector, which is reduced by a proportionalintegral-derivative (PID) controller through variation of the roll angle activation window. The total projectile inertial trajectory error $\Gamma$ and the error command angle $\gamma$ are defined in Eqs. (10) and (11):

$$
\begin{gathered}
\Gamma=\sqrt{e_{y}^{2}+e_{z}^{2}} \\
\gamma=\tan ^{-1}\left(\frac{e_{z}}{e_{y}}\right)
\end{gathered}
$$

The error command angle and roll angle activation window are then input into the model prediction algorithm in Fig. 20, where $\gamma$ provides an inertial direction for roll angle activation and $\delta$ specifies 


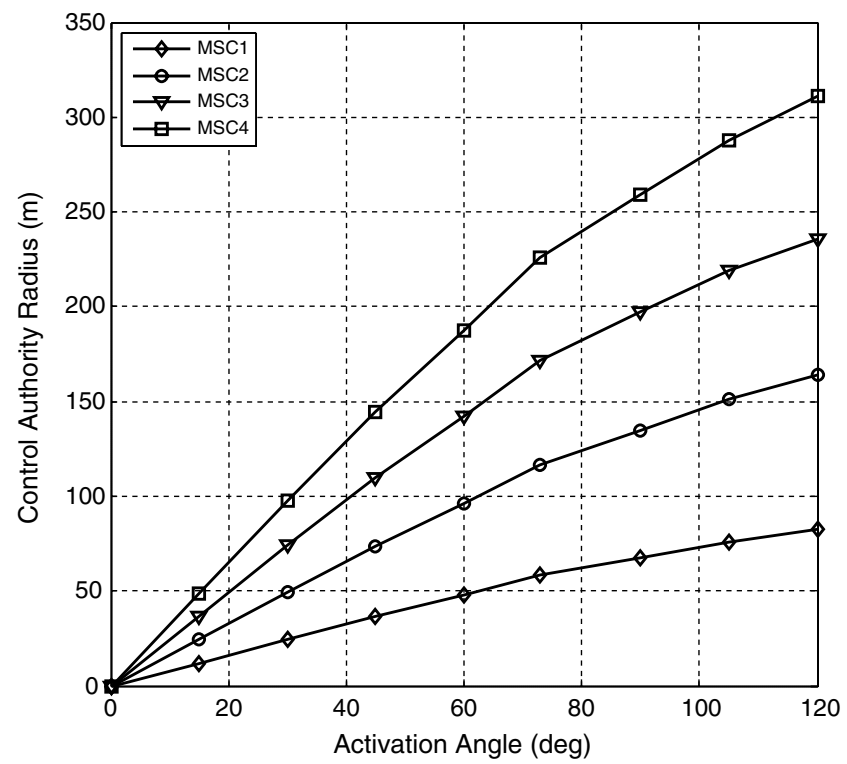

Fig. 16 Trade study: effect of varied activation angle $\delta$ on full control authority with nominal conditions: $t_{a}=1.0 \mathrm{~s}$ and $M a_{i}=3.0$.

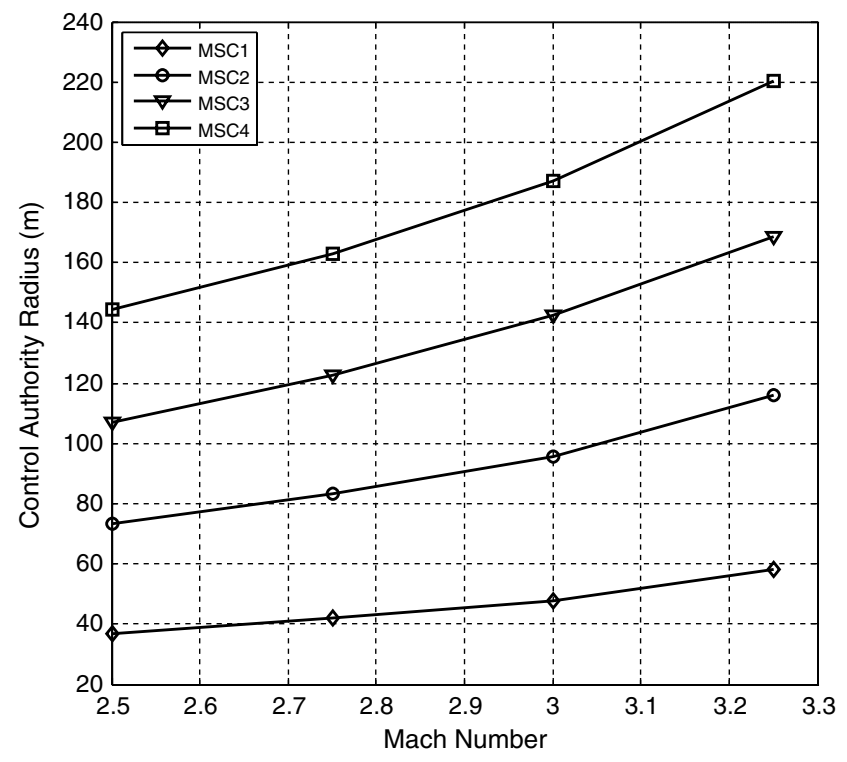

Fig. 17 Trade study: effect of varied launch Mach number $M a_{i}$ on full control authority with nominal conditions: $t_{a}=1.0 \mathrm{~s}$ and $\delta=60 \mathrm{deg}$.

an angle band about $\gamma$ for activation. The chosen command trajectory consisted of 30 discrete points that are linearly interpolated by the controller during flight and was generated by the nominal initial conditions previously used to simulate "perfectly shot" ideal

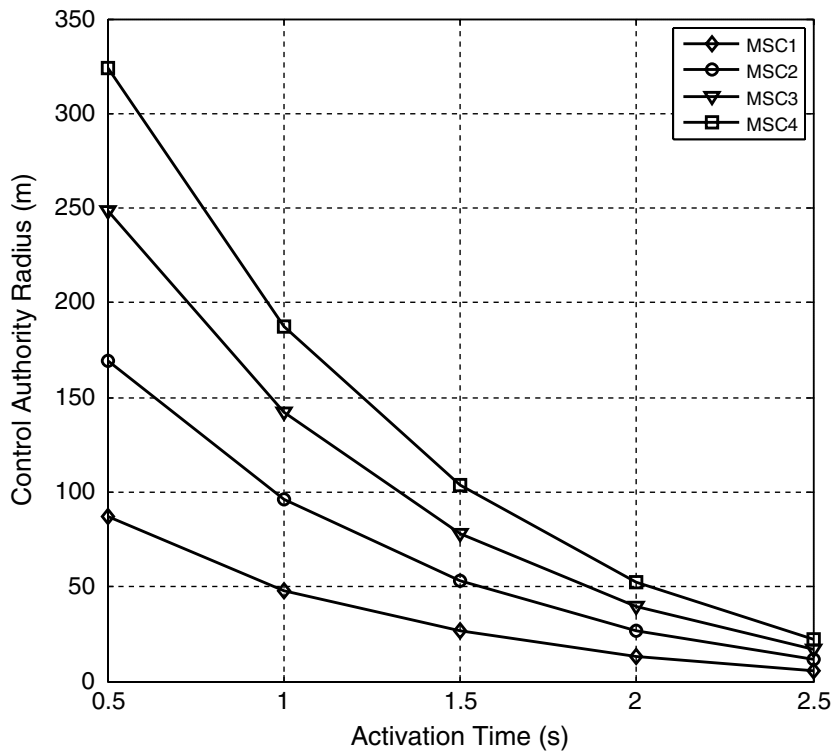

Fig. 18 Trade study: effect of varied control system activation time $t_{a}$ on full control authority under nominal conditions: $\delta=60 \mathrm{deg}$ and $M a_{i}=3.0$.

projectile. Next, the following perturbed initial conditions were used for controlled and uncontrolled trajectories: $x=0.0 \mathrm{ft}, y=0.0 \mathrm{ft}$, $z=-10.0 \mathrm{ft}, \quad \phi=0.0 \mathrm{rad}, \quad \theta=0.018 \mathrm{rad}, \quad \psi=0.01 \mathrm{rad}, \quad u=$ $3360 \mathrm{ft} / \mathrm{s}, \quad v=-1.14 \mathrm{ft} / \mathrm{s}, \quad w=1.79 \mathrm{ft} / \mathrm{s}, \quad p=0.17 \mathrm{rad} / \mathrm{s}, \quad q=$ $-0.79 \mathrm{rad} / \mathrm{s}$, and $r=0.73 \mathrm{rad} / \mathrm{s}$. For the controlled case, the roll angle activation window was limited to a maximum value of $\delta_{\max }=90.0 \mathrm{deg}$. Also, $t_{a}=1.0 \mathrm{~s}, K_{P}=0.363, K_{I}=0.00154$, and $K_{D}=0.0675$.

Figures 21-26 show the performance of the controlled projectile. Figures 21 and $\underline{2} 2$ demonstrate the controlled projectile's ability to quickly track the command trajectory soon after activation. Note that the uncontrolled shot misses the target (considered to be impact point of the commanded trajectory) by $-2.90 \mathrm{~m}$ in altitude and $30.65 \mathrm{~m}$ in deflection, while the controlled shot misses the target by $0.60 \mathrm{~m}$ in altitude and $-0.76 \mathrm{~m}$ in deflection.

Figure 23 shows that the controlled projectile total angle of attack reaches a maximum value of $8.84 \mathrm{deg}$ upon control maneuver activation but then drops below $5.0 \mathrm{deg}$ within $1.0 \mathrm{~s}$. Figure 24 shows variation in the error command angle after control maneuver activation. At first this angle remains nearly constant at approximately $180.0 \mathrm{deg}$ and then steadily descends. This implies that, once the controller is activated, the projectile turns left to approach the command trajectory and then starts to spiral about it in a clockwise manner, as it seeks the command trajectory. Figure 25 shows that the total inertial error is rapidly reduced from $10.28 \mathrm{~m}$ to approximately $0.76 \mathrm{~m}$ after control maneuver activation and then levels off. This suggests that once the projectile has "snapped" to the command trajectory and has begun to spiral about it, it does so at a nearly constant radius of $0.76 \mathrm{~m}$. Figure 26 shows the time history of the roll

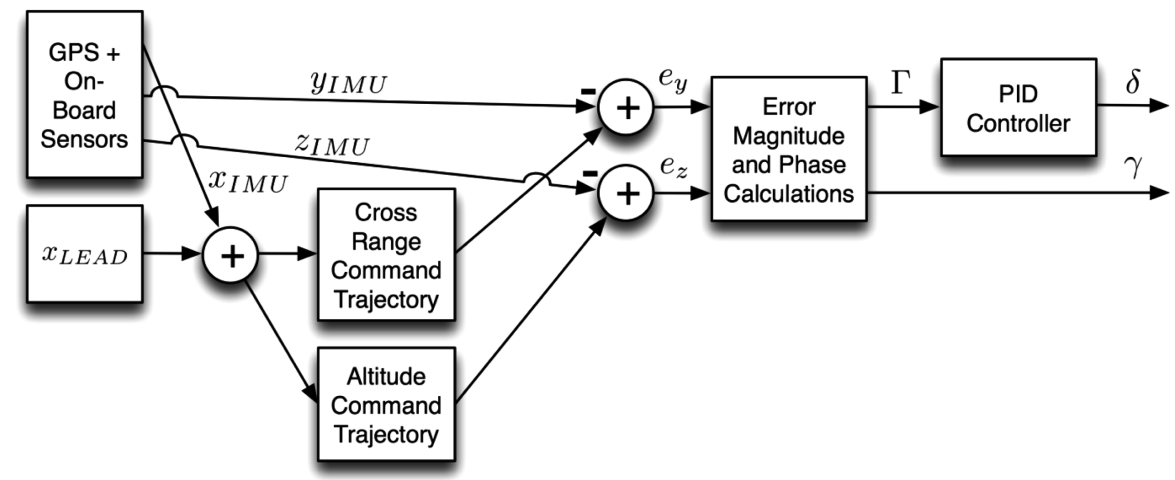

Fig. 19 Microspoiler control system logic (part I). 


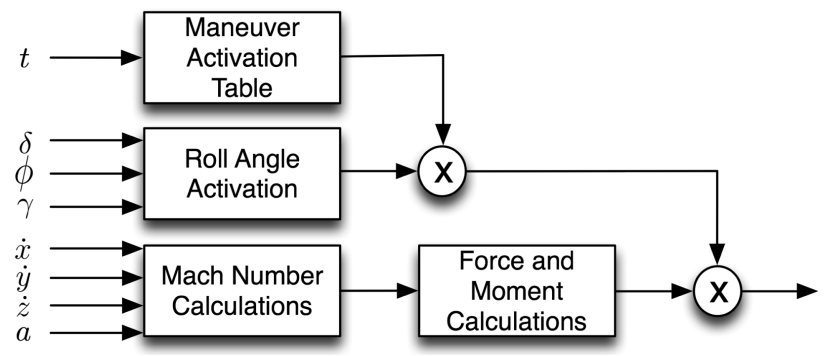

Fig. 20 Microspoiler control system logic (part II).

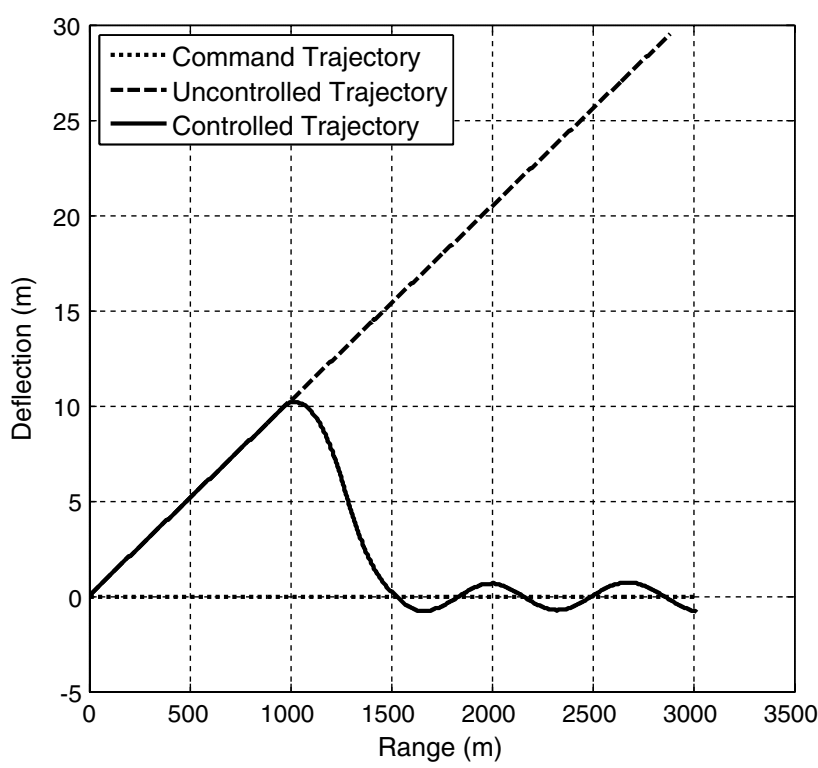

Fig. 21 Deflection vs range (active control case).

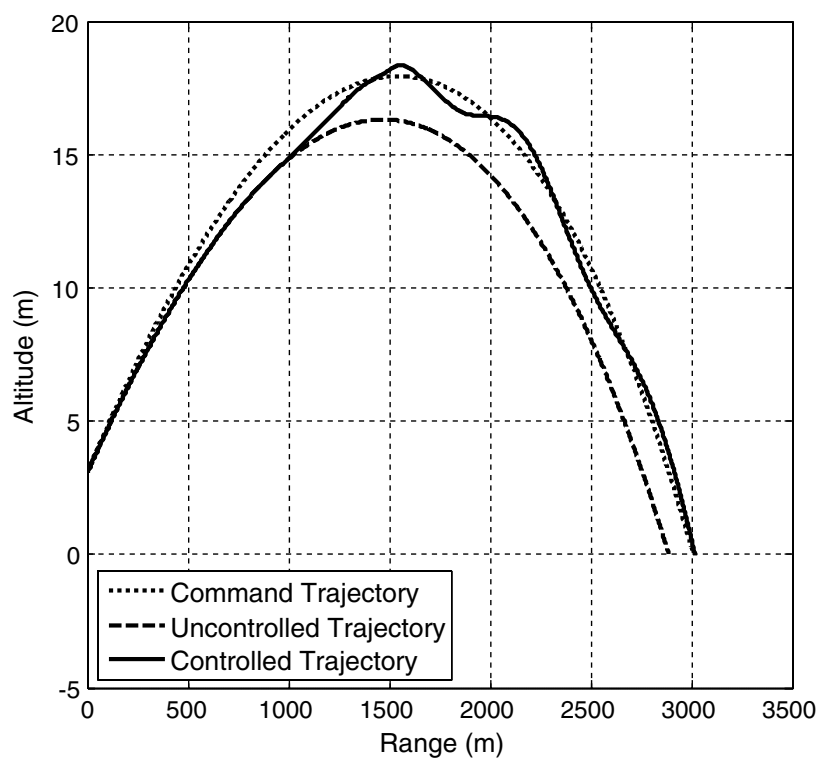

Fig. 22 Altitude vs range (active control case).

angle activation window after control maneuver activation, which is at first constant (since maximum control authority is initially needed) but is then reduced down to average out at approximately $55.0 \mathrm{deg}$.

\section{Dispersion Analysis}

Monte Carlo dispersion cases were computed to demonstrate the performance of the control system with perturbed initial conditions (tipoff effects) and projectile mass/inertial property uncertainty. To simulate tipoff effects, initial states were perturbed from the nominal

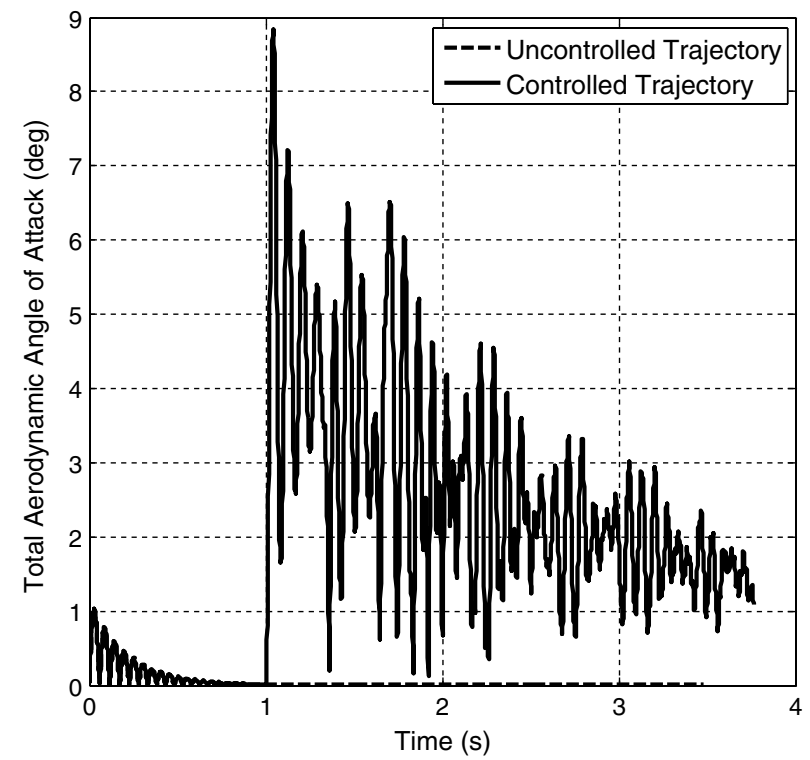

Fig. 23 Angle of attack vs time.

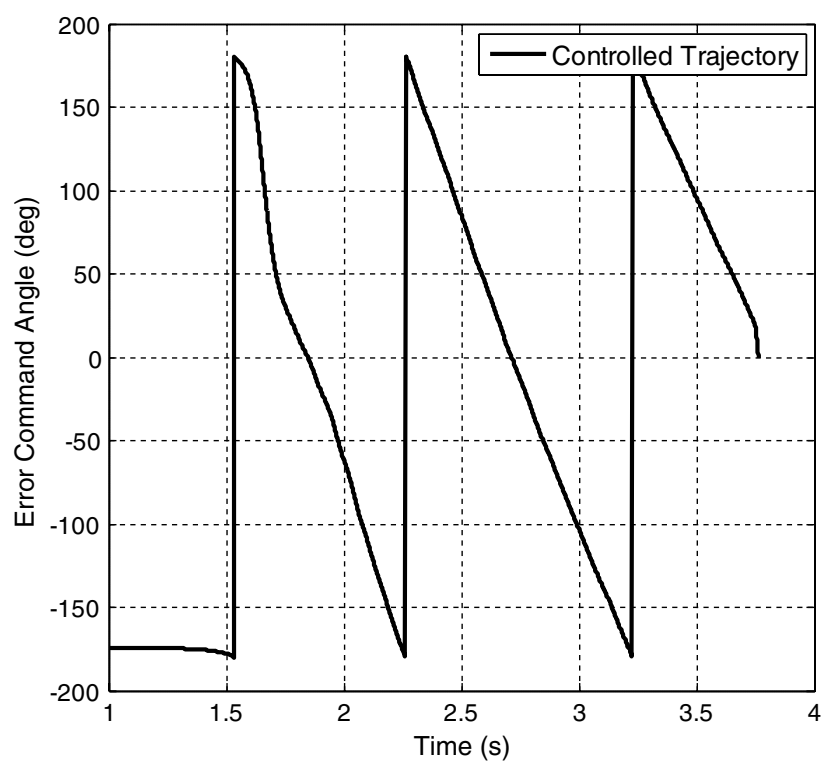

Fig. 24 Error command angle vs time, after controller activation.

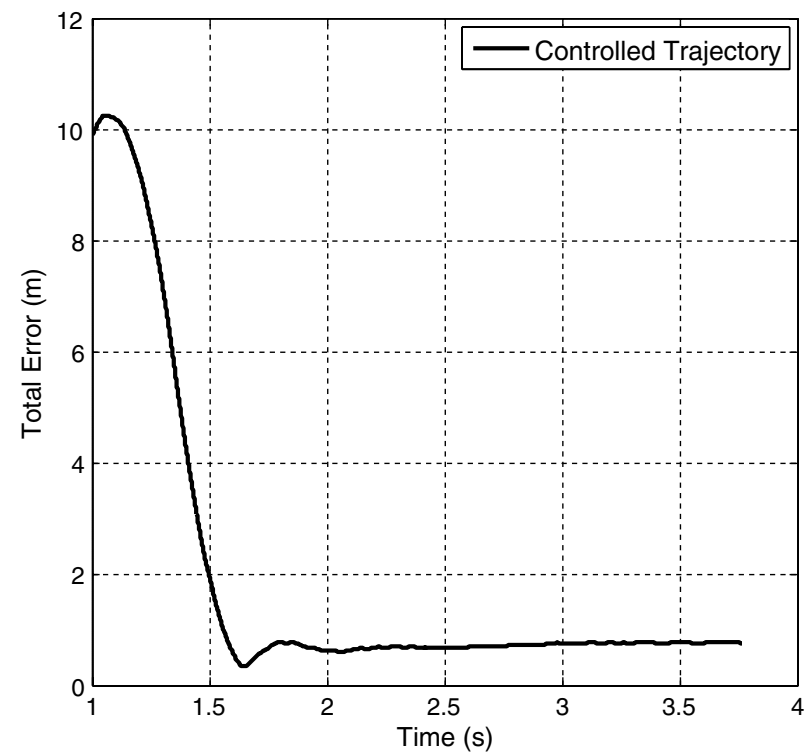

Fig. 25 Total error vs time, after controller activation. 


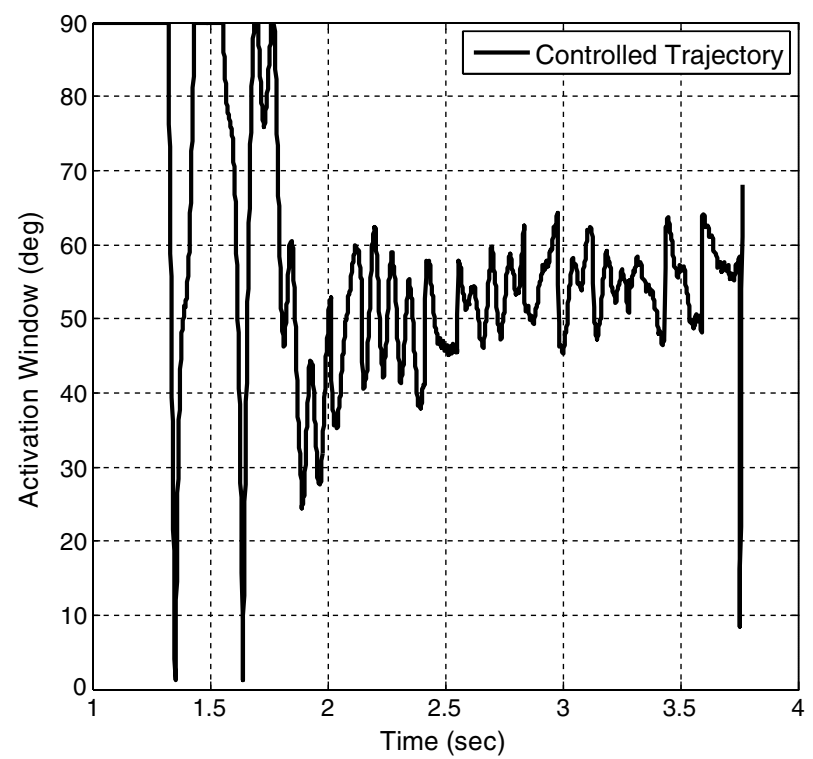

Fig. 26 Roll angle activation window vs time, after controller activation.

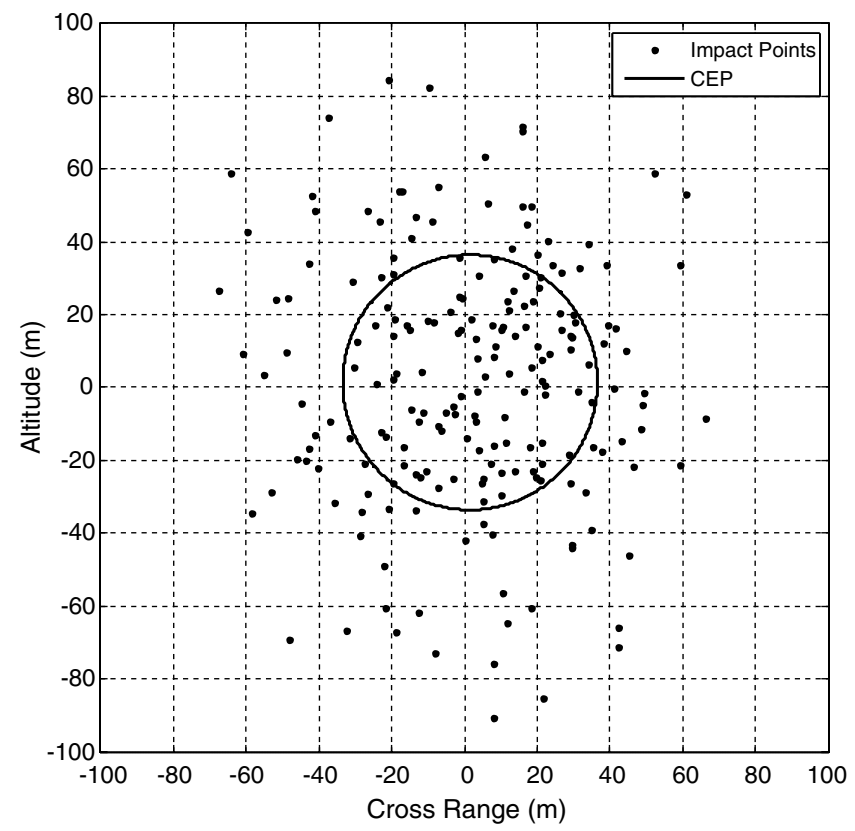

Fig. 27 Monte Carlo dispersion (Circular error probable [CEP] $=$ $35.01 \mathrm{~m}$ centered at the mean impact point) for an uncontrolled projectile with variation in gun launch tipoff, wind intensity and direction, and projectile mass/inertia properties at an impact range of $3.0 \mathrm{~km}$.

conditions, which include initial pitch angle, initial yaw angle, initial muzzle velocity, initial crossing velocities in the $y$ and $z$ directions, initial roll rate, initial pitch rate, and initial yaw rate. The standard deviations for these values are $0.01 \mathrm{rad}, 0.01 \mathrm{rad}, 3.0 \mathrm{ft} / \mathrm{s}, 1.0 \mathrm{ft} / \mathrm{s}$, $1.0 \mathrm{ft} / \mathrm{s}, 0.15 \mathrm{rad} / \mathrm{s}, 0.7 \mathrm{rad} / \mathrm{s}$, and $0.7 \mathrm{rad} / \mathrm{s}$, respectively. To simulate variability in projectile weight, diameter, stationline center of gravity, and moment of inertias about the $x, y$, and $z$ body axes, these parameters where modeled as uncertain with standard deviations of $0.0837 \mathrm{lbf}, 0.000052 \mathrm{ft}, 0.00053 \mathrm{ft}, 0.000000268$ slugs- $\mathrm{ft}^{2}$, 0.0000189 slugs- $\mathrm{ft}^{2}$, and 0.0000189 slugs- $\mathrm{ft}^{2}$, respectively. The effect of atmospheric wind was simulated using a simple atmospheric mean wind model. A horizontal mean wind direction $\psi_{\mathrm{MW}}$ was randomly chosen between $0.0-360.0 \mathrm{deg}$, for a mean wind intensity $\sigma_{\mathrm{MW}}$ with standard deviation $0.5 \mathrm{ft} / \mathrm{s}$.

Figures 27 and 28 show the impact point results in a vertical plane at a range of $3.0 \mathrm{~km}$ for the uncontrolled and controlled dispersion

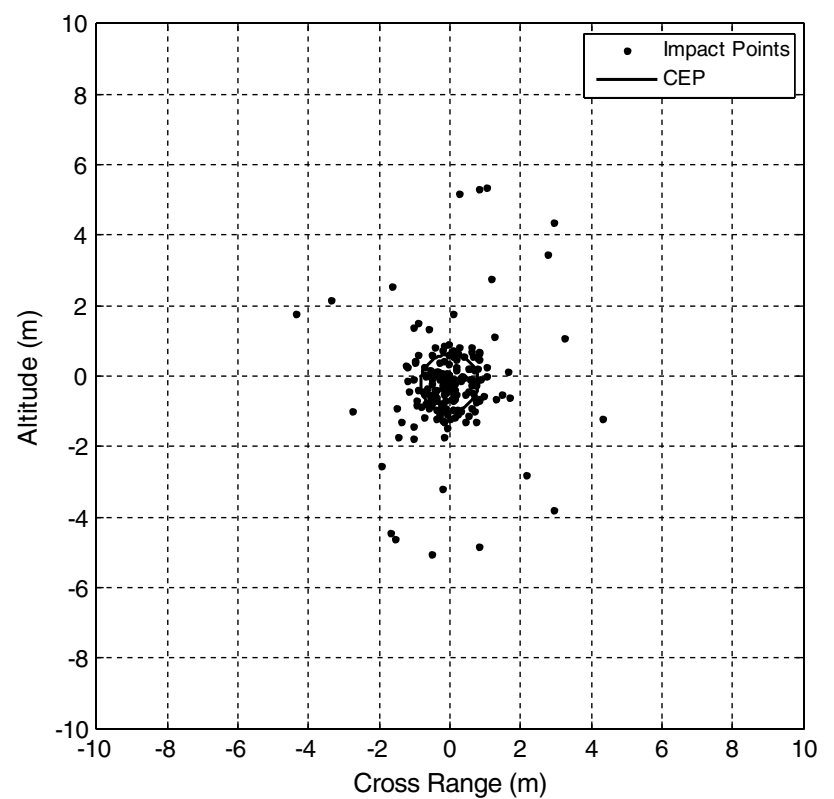

Fig. 28 Monte Carlo dispersion (Circular error probable [CEP] = $0.82 \mathrm{~m}$ centered at the mean impact point) for a controlled projectile with variation in gun launch tipoff, wind intensity and direction, and projectile mass/inertia properties at an impact range of $3.0 \mathrm{~km}$.

cases. As observed, implementation of the microspoiler control system causes a $97.66 \%$ reduction in the circular error probable (CEP)—from $35.01 \mathrm{~m}$ (uncontrolled) down to $0.82 \mathrm{~m}$ (controlled). Note that the CEP was calculated about the mean impact values for each case. These results indicate that the microspoiler smart projectile control mechanism is capable of reducing trajectory tracking errors down to sensor accuracy.

\section{Conclusions}

The microspoiler concept for active control of finned projectiles in supersonic flight is a viable physical control mechanism that provides high maneuverability to the round. Control authority is linearly increased with the number of microspoilers. Increasing the roll angle activation window also increases control authority, but a point of diminishing return is reached beyond an angle of $110.0 \mathrm{deg}$. Increasing projectile launch muzzle velocity and decreasing control system activation time are also observed to have positive effects on control authority. The proportional-integral-derivative-controlled dispersion results show that the microspoiler mechanism is capable of reducing error down to sensor error. The conclusions of this study are reached using six-degree-of-freedom flight dynamic simulation with microspoiler aerodynamic loads provided by computational fluid dynamics modeling. These results highlight the promise of this control mechanism for high-speed actively controlled projectiles and rockets.

\section{Acknowledgments}

This project was made possible by support from U. S. Army Research Laboratories in Aberdeen, Maryland. Notable contributions to this project include Dan Cler of Picatinny Arsenal, New Jersey, and Robert Carson and Robert Dillon of Benét Laboratories in Watervliet, New York. Also, Jorge de la Mata, an undergraduate research assistant at Georgia Institute of Technology aided in conducting trade study results from trajectory flyout simulations.

\section{References}

[1] Rogers, J., and Costello, M., "Control Authority of a Projectile Equipped with a Controllable Internal Translating Mass," AIAA Paper 2008-6492, 2007.

[2] Richardson, D., "Summoning the Fire," Armada International, Vol. 27, No. 1, 2003, p. 10. 
[3] Gander, T. J., "Artillery on Target-Trajectory Correctable Munitions," Armada International, Vol. 27, No. 2, 2003, p. 70.

[4] Massey, K., McMichael, J., Warnock, T., and Hay, F., "Mechanical Actuators for Guidance of a Supersonic Projectile," AIAA Paper AIAA2005-4970, 2005.

[5] Massey, K. C., and Guthrie, K. B., "Optimized Guidance of a Supersonic Projectile Using Pin Based Actuators," AIAA Paper 20054966, 2005.

[6] Massey, K. C., and Silton, S. I., "Testing the Maneuvering Performance of a Mach 4 Projectile," AIAA Paper 2006-3649, 2006.

[7] Bell, M., Watterson, J. K., and Lisk, D., "A Numerical Study into a Local Protuberance Interaction with a Fin on a Supersonic Projectile," AIAA Paper 2009-1092, 2009.

[8] McCoy, R. L., Modern Exterior Ballistics, Schiffer Publishing Ltd., Atglen, PA, 1999, pp. 187-221.

[9] Murphy, C. H., "Free Flight Motion of Symmetric Missiles," U.S. Army Ballistic Research Laboratories, BRL Rept. No. 1216, 1963.

[10] Costello, M., and Anderson, D., "Effect of Internal Mass Unbalance on the Terminal Accuracy and Stability of a Projectile," AIAA Flight Mechanics Conference, San Diego, CA, AIAA Paper 1996-3447, July 1996.

[11] Costello, M., and Sahu, J., "Using CFD/RBD Results to Generate Aerodynamic Models for Projectile Flight Simulation," Journal of Aerospace Engineering, Proceedings of the Institution of Mechanical Engineers, Part G, Vol. 222, 2008, pp. 1067-1079.

[12] Sahu, J., "Time-Accurate Numerical Prediction of Free-Flight Aerodynamics of a Finned Projectile," Journal of Spacecraft and Rockets, Vol. 45, No. 5, 2008, pp. 946-954. doi: $10.2514 / 1.34723$

[13] Montalvo, C., and Costello, M., "Estimation of Projectile Aerodynamic Coefficients Using Coupled CFD/RBD Simulation Results," AIAA Paper 2010-8249, 2010.
M. Miller Associate Editor 